\title{
FACTORS AFFECTING THE WEAR RESISTANCE OF FORGING TOOLS
}

\begin{abstract}
The durability of forging tools is a function of many variables: tool heat treatment, surface quality, temperature, pressure, number of forgings, diffusion layers (nitriding) and many others. The objective of study was to analyze and compare the working conditions of forging tools. For the analysis of selected flat surfaces of tools. Analyzed forging dies subjected to normal use. Presented results of laboratory tests. The effect of temperature and time on the properties of the surface layer of forging tools. The results were compared with the literature data. This article shows the results of microhardness tests for forging dies which have forged the corresponding number of forgings. The results of laboratory studies on microhardness of hot working steel 1.2344 in the furnace at various temperatures and time are also presented. The working conditions of the forging tools are very complex. The most often described in the literature are: thermal fatigue, abrasive wear, mechanical fatigue and cracks. The article discusses the effects of increased temperature on the surface properties of forging tools. Forging dies were made of hot work tool steel 1.2344. FEM modeling of changes in the surface layer should take into account changes in tool hardness as a function of time (number of forgings).

Keywords: hot die forging, wear mechanism, forging, laboratory thermal test
\end{abstract}

\section{Introduction}

The mutual relations of the particular degradation mechanisms of forging tools significantly vary and depend mainly on the operation conditions under which the forging process is conducted. Forging die inserts used in the industrial hot forging processes characterize in a relatively low hardness, which directly translates to both the quality and the cost of the forging production. To a lesser extent, the tool's resistance to degradation mechanisms depends on its construction (shape of the working surface), the tool material and its appropriate thermal treatment as well as surface layer treatment; the least influence is exerted by the shape of the preform [6,7].

In the case of forging tools, the option of applying a lubricating and cooling agent is significant. Usually, during semi-free die forging (upsetting, flattening, etc.), the tools are not lubricated due to the complicated flow of the deformed material. This case is different from the one of typical die forging, during which the application of a lubricant is required in order to minimize the friction, aiming at precise filling of the working pattern of the tool by the deformed material. During the operation of upsetting, scale is removed (periodically cleaned off by the forger), which also can affect the durability. This makes the operation conditions for non-lubricated, and thus non-cooled, tools to be different from the ones for lubricated tools. A little different case is with forging tools which are not lubricated or cooled, for which the typical degradation mechanism is abrasive wear and plastic deformation $[3-5,7,10]$. The research performed by the authors concerning the analysis of the surface layer of forging tools showed that, in the case of forging processes conducted at elevated temperatures, for typical tool work conditions (lubrication and cooling), the percentage of abrasive wear as the dominant degradation mechanism decreases [11-12], and the participation of thermo-mechanical fatigue significantly increases, this process being the one which accelerates the visible and easily measured abrasive wear, as a result of which the tools are removed from production [13-14].

\section{Industrial forging process}

Of the many types of treatments and tools used for hot forging author encouraged to submit two types of treatments often encountered forging. These are:

\section{- Upsetting}

- $\quad$ Forging

Presented at work refers to the process of upsetting forging axisymmetric and is used to flatten the pre-heated material and remove it from the scale. Forging process in the second operation consists in shaping of the material before was upsetting.

The objective of study was to analyze and compare the working conditions of forging tools. For the analysis of selected

\footnotetext{
* WROCLAW UNIVERSITY OF SCIENCE AND TECHNOLOGY, DEPARTMENT OF METAL FORMING AND METROLOGY, 5 LUKASIEWICZA STR., 50-371 WROCŁAW, POLAND

\# Corresponding author: maciej.zwierzchowski@pwr.edu.pl
} 
flat surfaces of tools. In addition, the paper presents research results:

- The effect of temperature and heating time on the hardness of the surface layer (without nitrided layer),

- The effect of temperature and heating time on the hardness of the surface layer (with nitrided layer) The main difference between the operations in question are forging:

- temperature of tools,

- lubrication,

- shape tools,

- the number of forgings (tool life).

Tools were made from the same grade tool steel, hot work $\mathrm{X} 40 \mathrm{CrMoV} 5-1$. Was carried typical heat treatment or hardening + tempering twice tools in the range of $525-550^{\circ} \mathrm{C}$. In addition to the stamping tools they were nitrided. The thickness of the nitrided layer was approx. $250 \mu \mathrm{m}$. A general view of the upsetting tool and stamping shown in Figure 1d and 1e. Figure 1a, $1 \mathrm{~b}$ and $1 \mathrm{c}$ show forging after first, second and third forging operations. The forging diameter is $196.5 \mathrm{~mm}$ and its height is $30 \mathrm{~mm}$.

Upsetting process is quite simple but the thermal loading and tool wear is relatively large. The advantage is the possibility to adjust the height of clamping tools, thus correcting excessive tool wear. Average life of these tools to upsetting is approx. 20 thousand forgings. Tools for preliminary forging have a much lower life of approx. 10 thousand forgings. Unfortunately they wear evenly on all surfaces. Therefore, when the regeneration is required machining, welding and re-machining to give the corresponding matrix shape. In addition it may be applied in heat treatment of the deposited gear to increase hardness.

Tools for forging preliminary have a much lower life of approx. 10 thousand. forgings. Unfortunately they wear evenly on all surfaces. Therefore, when the regeneration is required machining, welding and re-machining to give the corresponding matrix shape. In addition it may be applied in heat treatment of the hard coated tools to increase hardness.

\section{Conditions of work tools}

As noted earlier the fundamental difference in terms of thermal conditions is the lack of cooling die upsetting. Preliminary forging dies are cooled suspension of $4 \%$ graphite in water. Their average temperature during operation is approx. $250-300^{\circ} \mathrm{C}$ (Fig. 2). For the tools that are not cooled by the standard operating temperature is much higher and amounts to approx. $500-550^{\circ} \mathrm{C}$.

Due to the high thermal loading tools and high temperature of the surface layer upon contact with the hot forging tool, a decrease of hardness. The loss of stability nitrided layer and a decrease in hardness of the surface layer without nitrided layer deepens with the increasing number of forgings. No cooling intensifies the process of tempering. The decrease in microhardness tools upsetting the surface shown in Figure 3.

We can see that in the middle of the tools (P1 in Fig. 3 and P1 and P3 in Fig. 4), the largest decrease in hardness of the surface layer. This is caused by the longest contact material forgings of tool. Forgings are put in this place during the process of forging products. As the amount of forging (hot forging a contact time with the tool) where the microhardness is reduced to approx. $300 \mathrm{HV}$. This low hardness is one of the main causes of wear of forging tools for hot working. Another process intensifier wear is the thermal fatigue of the material resulting in a loss of cohesion of the material in the surface layer.

Below are presented photographs (Figs. 5-7) microscopic surface working tools upsetting the forging of $550 \mathrm{pcs}, 7.000 \mathrm{pcs}$ and 9.000 pcs. Figure 8 shows an example of a crack from the area 1 of die forging the 9.000 pcs forgings. Crack is deformed plastically as evidenced by the shape and microhardness measurements in this area (Fig. 3). Visible are also layered oxides formed in the area of fracture (Fig. 8). The reason for the formation of the oxide layer is high temperature in the surface layer in excess of $500-550^{\circ} \mathrm{C}$.
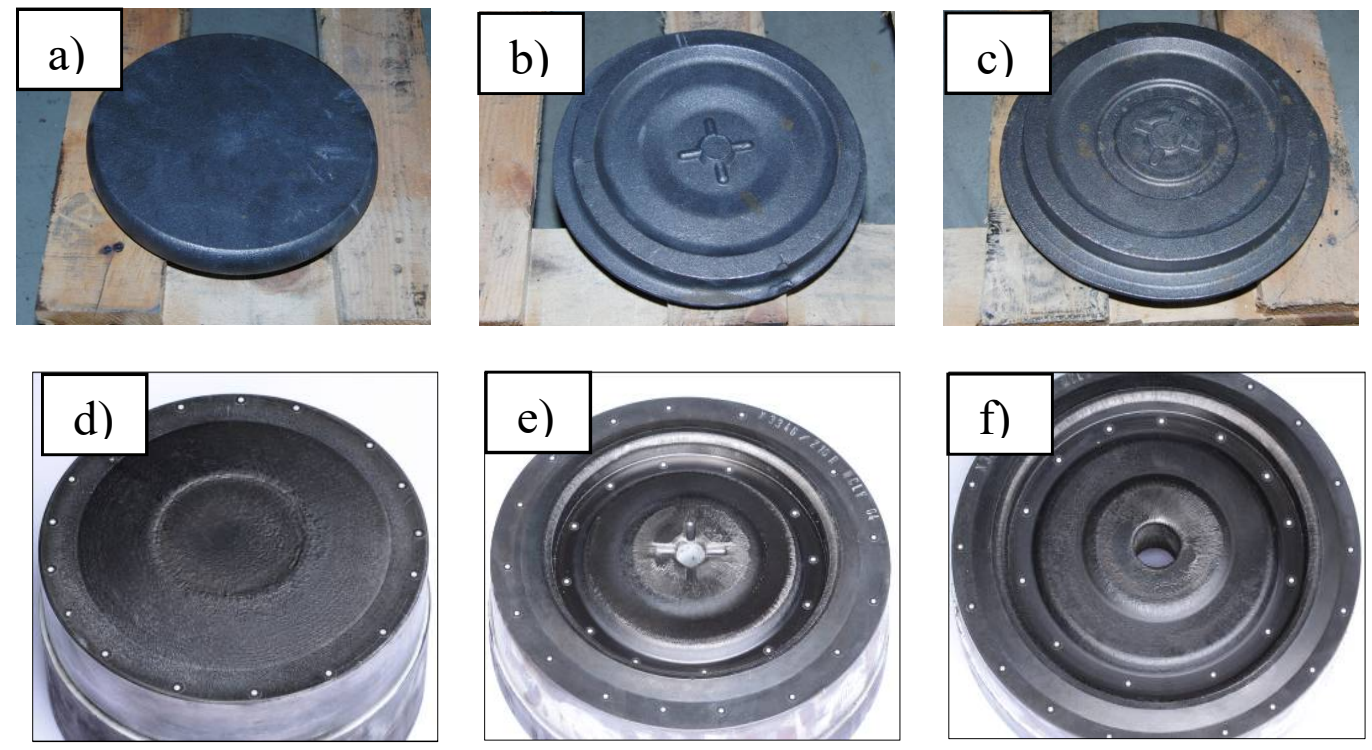

Fig. 1. Forgings after first a), second b), and third c) forging operations, d) the lower die upsetting, b) the lower forging die, 2nd operation, c) the lower forging die, 3rd operation 


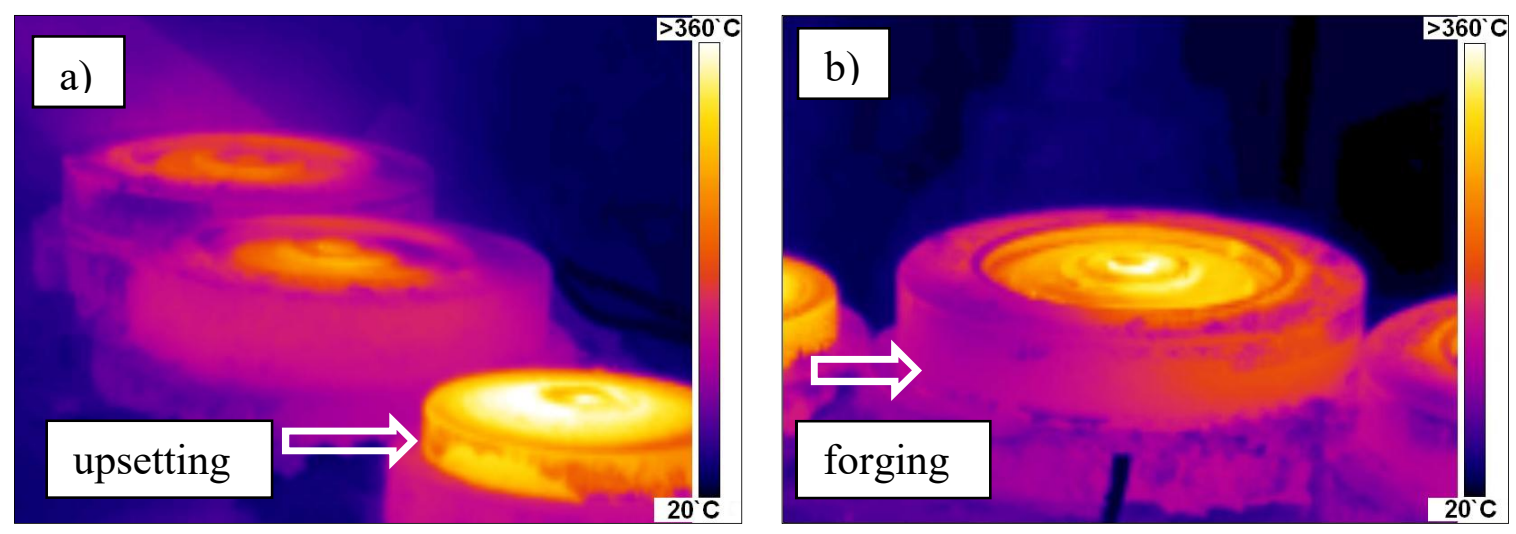

Fig. 2. Infrared imager lower dies for hot forging. a) die upsetting, b) preliminary forging die

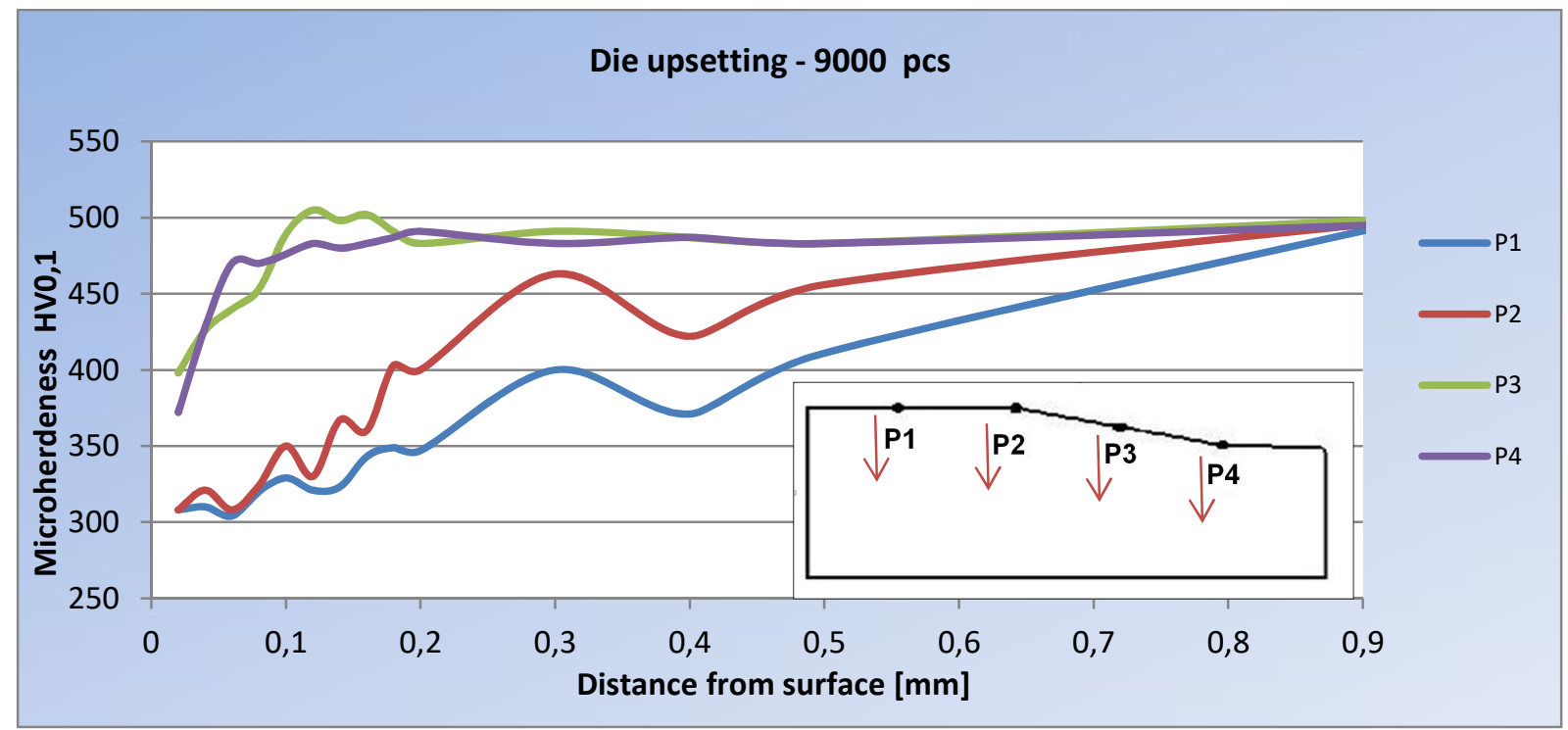

Fig. 3. Distribution of microhardness as a function of distance from the surface for 4 selected punks measurement. The die upsetting the forging of 9 thousand. pes. Forgings

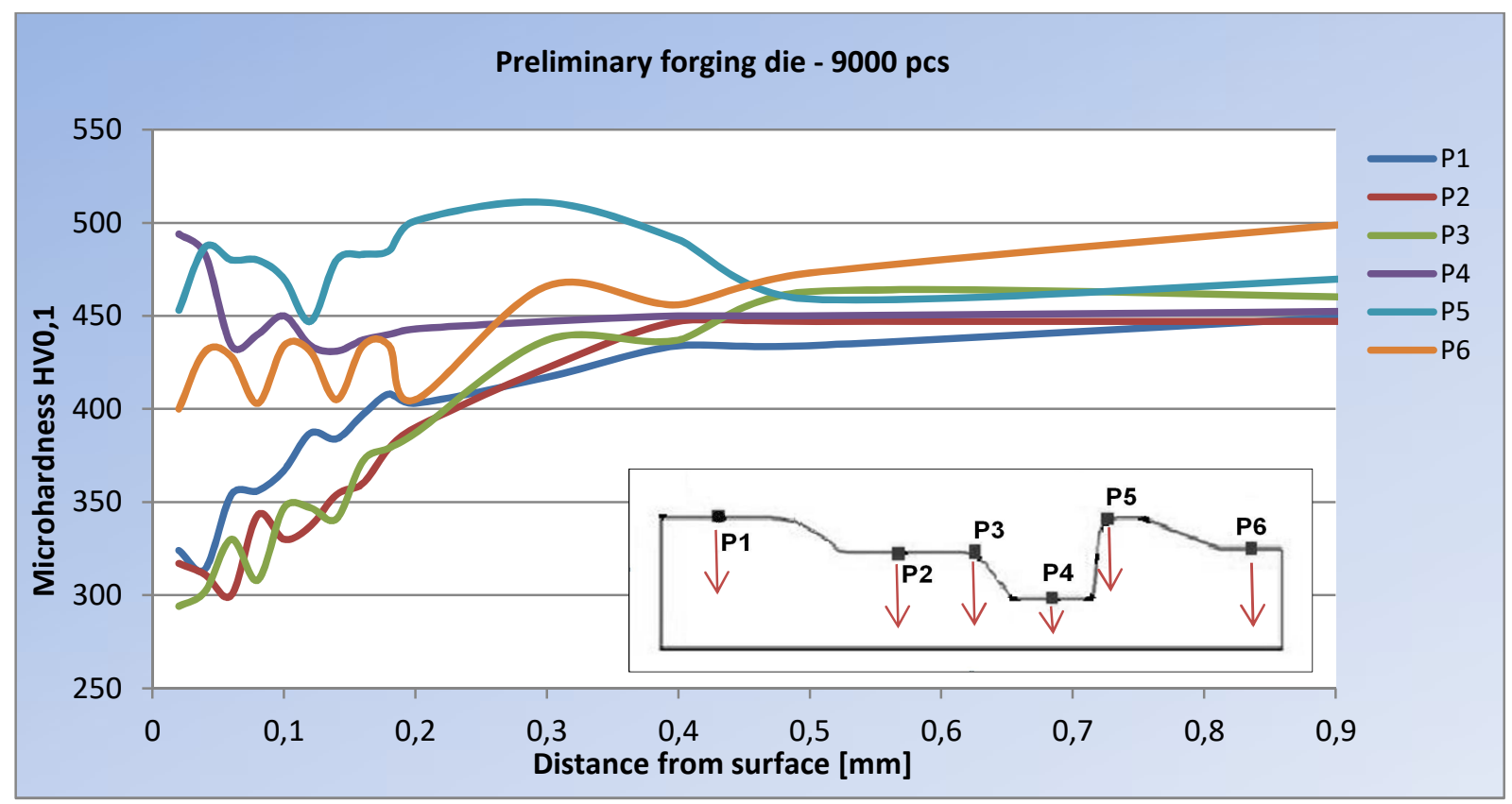

Fig. 4. Hardness distribution as a function of distance from the surface 6 to the selected measurement points. The preliminary die forging after forging 9 thousand. pcs. Forgings 
1570
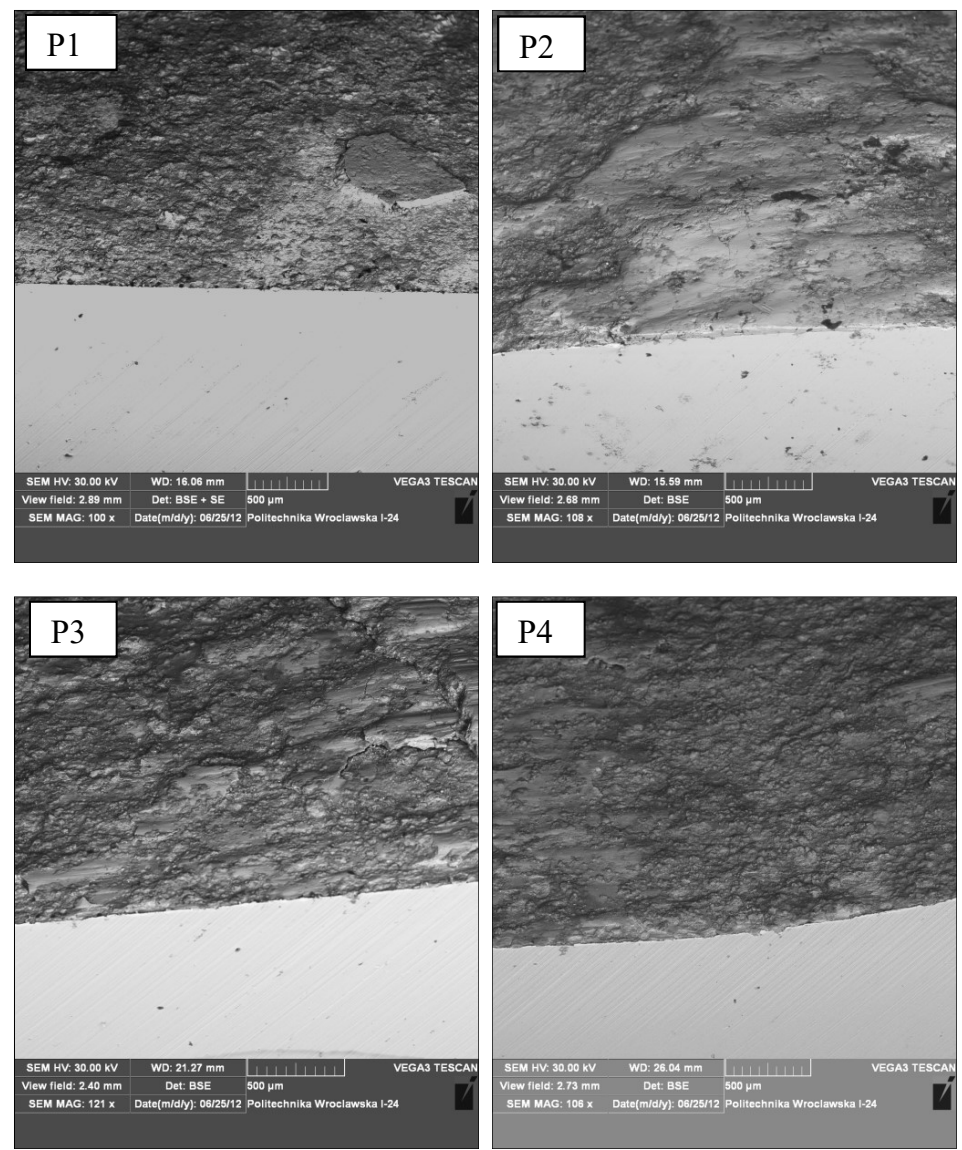

Fig. 5. Points 1-4 for the down upsetting die after 550 pieces forgings
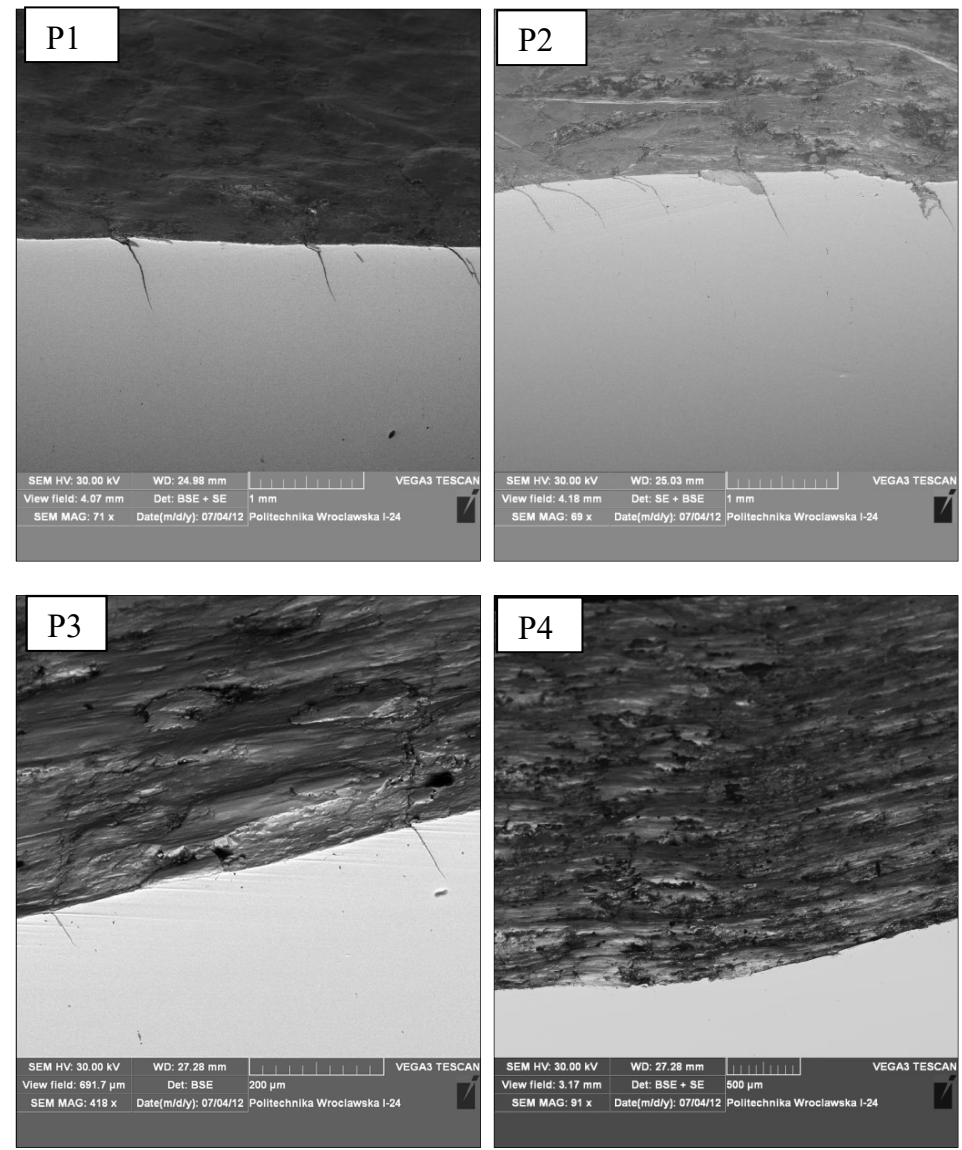

Fig. 6. Points 1-4 for the down upsetting die after 7000 pieces forgings 

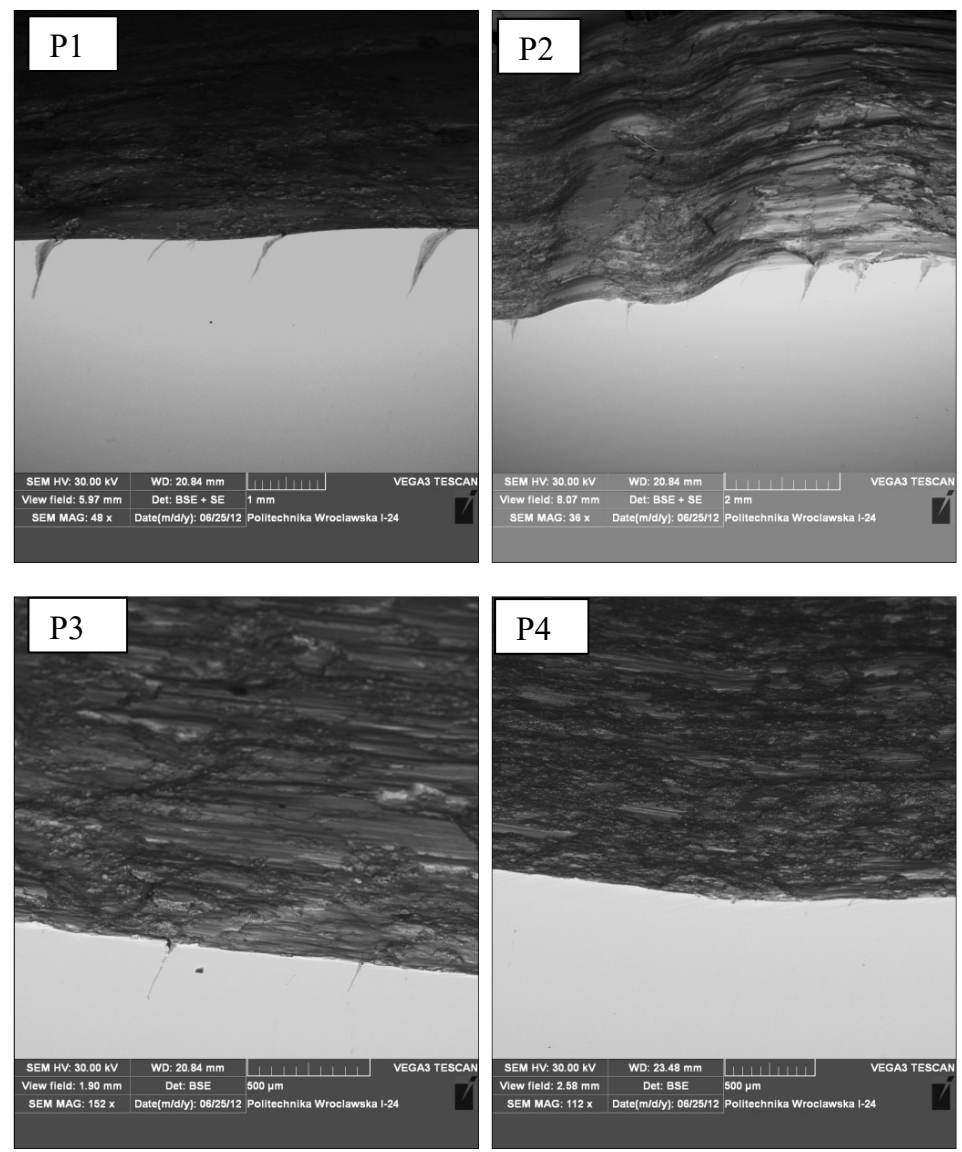

Fig. 7. Points 1-4 for the down upsetting die after 9000 pieces forgings
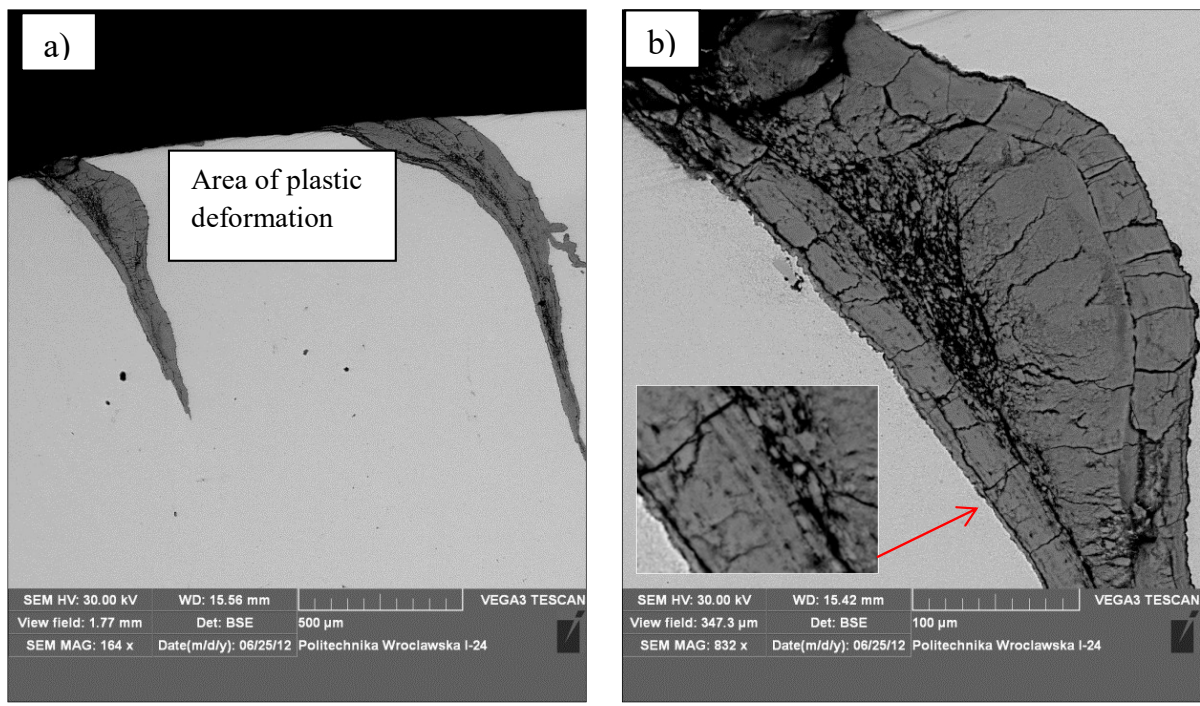

Fig. 8. a) View deformed plastically cracks formed in the early stage of work tools and b) layer formed oxides in the entire volume of the crack

When the surface layer is tempered, the hardness in the top layer is decreasing, the cracks deform plastically. Depth of change is even $100-200 \mu \mathrm{m}$.

J.H. Kang in their studies $[1,2]$ modifies the model of Archard taking into account the impact of a decrease of hardness as a function of time and the change in process parameters due to tool wear. As described in his papers [1-2] J.H. Kang hardness as a function of time is described for the place where occurred the greatest tool wear (Fig. 9).
In Figures 3 and 4 shows the hardness distribution as a function of distance from the surface to the selected four points. The figure below shows the average microhardness in the surface layer (depth $0.02 \mathrm{~mm}$ ) versus the amount of forgings.

We observed a clear decrease in hardness at forging have a small amount of 500 pieces forgings. Discussed above graph refers to tools not nitrided and the place marked as an area 2 where the tool wear is greatest. Analyzed the areas of greatest wear are flat parts of the tools, and there was observed type layer 


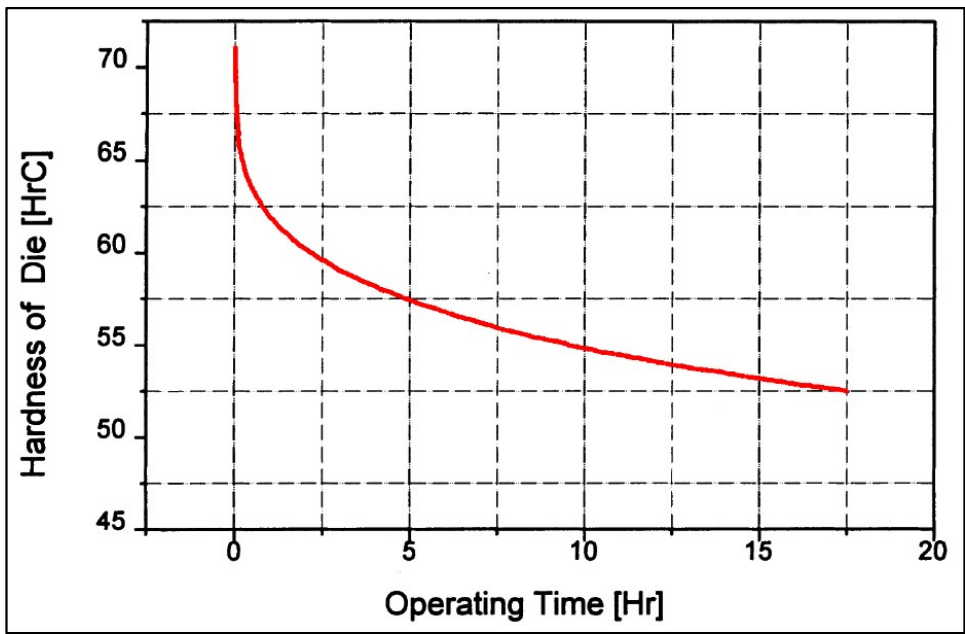

Fig. 9. Influence of time on the hardness of the tools in the place with the highest wear [1]
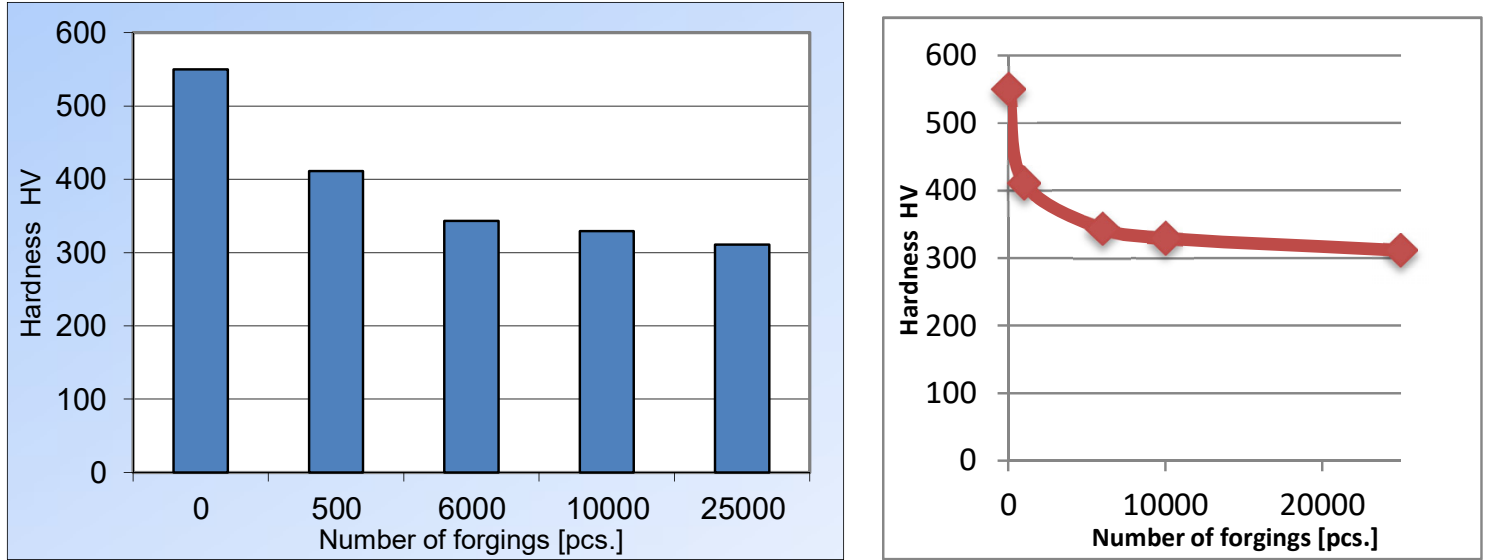

Fig. 10. Hardness in the surface layer as a function of the amount of forging die upsetting
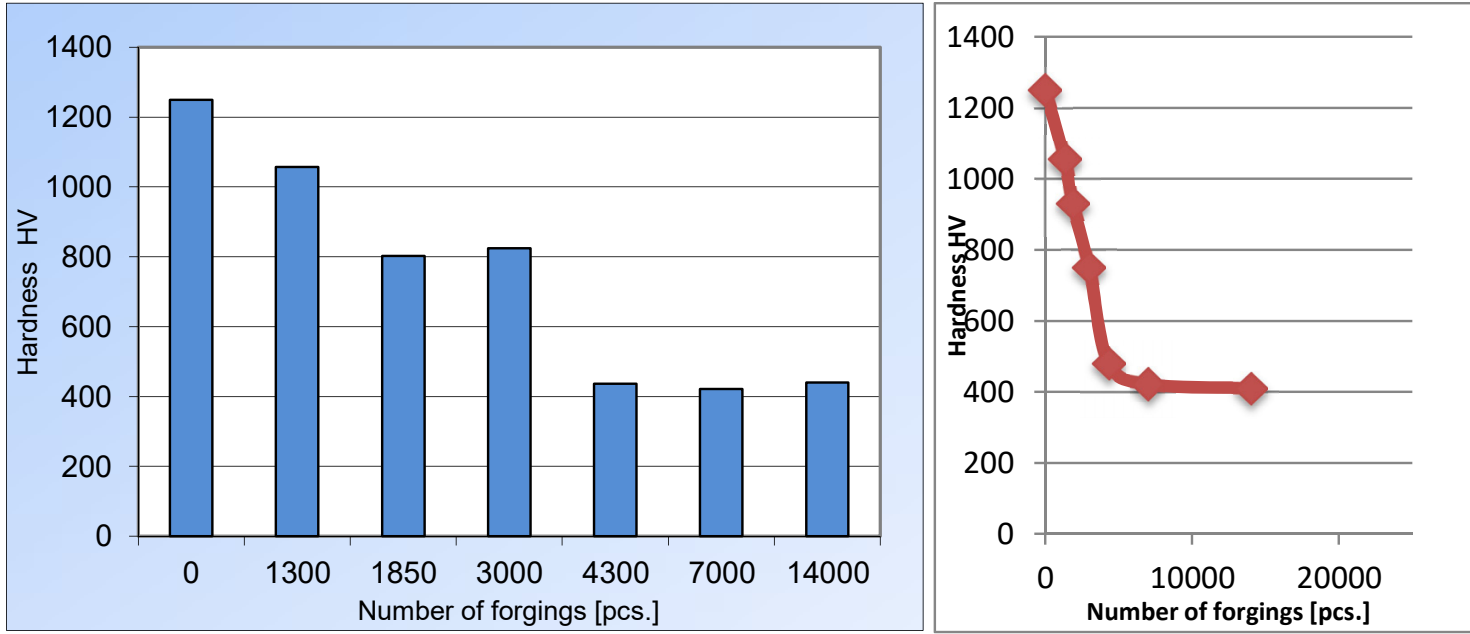

Fig. 11. Hardness as a function of the amount of forgings for the second operation (flat area in the middle of No.1 to Fig. 4)

"white layer" in these areas. A layer of this type occurs most frequently on the rays of the forging tools.

To determine the effect of heating time and temperature on the hardness of the surface layer was conducted laboratory tests. Tests were carried out without a protective atmosphere in order to reflect the actual working conditions of forging tools.
The analysis was performed for the samples nitrided and nonnitrided layer. The results of these studies are summarized below.

We observed a stronger effect of temperature on the stability of the nitrided layer. Higher temperature annealing $\left(650^{\circ} \mathrm{C}\right)$ causes a decrease in hardness of about $330 \mathrm{HV}$. Tempering at $550^{\circ} \mathrm{C}$ for a period of 2 hours causes a decrease in hardness of the 


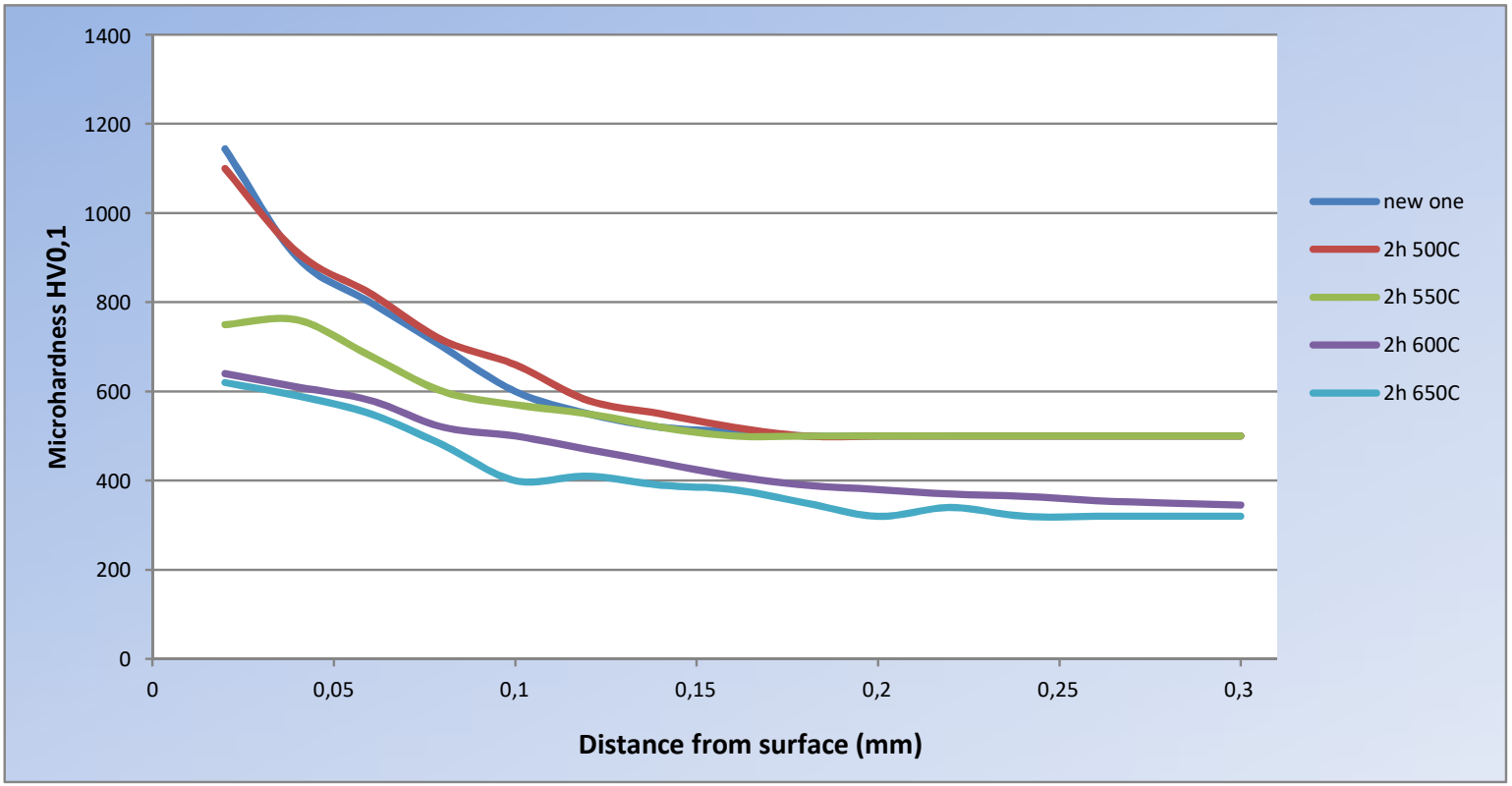

Fig. 12. Effects of temperature and heating time on hardness distribution in the surface layer for 1.2344 steel

nitrided layer to a value of approx. $700 \mathrm{HV}$. We can also observe no decrease in hardness to tempering at $550^{\circ} \mathrm{C}$ below the initial hardness of the core material (500-520HV).

The hardness of the respondents dies for hot forging and the hardness of the nitrided layer is a function of time and temperature (Fig. 11). Studies were carried out according to which, after approx. 4.000 pieces forgings followed by a gradual decrease in hardness in the surface layer. In the laboratory, this time amounts to 1-2 hours of heating at temperatures of $550-650^{\circ} \mathrm{C}$.

The decrease in the hardness of the nitrided layer is noticeable after the heating is at a temperature of $550^{\circ} \mathrm{C}$ after a time of $2 \mathrm{~h}$. Material with a layer of nitrided and tempered at $550^{\circ} \mathrm{C}$ hardness of the core is approx. $500 \mathrm{HV}$. Material with a layer of nitrided and tempered at $650^{\circ} \mathrm{C}$ hardness of the core drops to approx. 300HV.
During tempering the initial decrease in hardness caused by the advent of $\mathrm{Fe}_{3} \mathrm{C}$, is offset by the increase in hardness caused by fine carbide precipitates $\mathrm{V}_{4} \mathrm{C}_{3}$ (the effect of dispersion hardening). Only above $600^{\circ} \mathrm{C}$ temperature hardness decreases significantly because of the coagulation of precipitated carbides. The presence of chromium lowers the solubility of carbon in austenite, which in turn increases the amount of carbides in the steel [3-5]. Below are pictures of the microstructure of the surface layer of the material 1.2344 heat-preheated at $550^{\circ} \mathrm{C}, 600^{\circ} \mathrm{C}$ and $650^{\circ} \mathrm{C}$ by the time $2 \mathrm{~h}$.

No clear austenite precipitates. A large number of carbide precipitates. Due to the mechanism changes are likely carbides $\mathrm{MC}, \mathrm{M}_{2} \mathrm{C}$ and $\mathrm{M}_{7} \mathrm{C}_{3} . \mathrm{M}_{7} \mathrm{C}_{3}$-type carbides arises from changes in saturated cementite concentrated added alloy. $\mathrm{MC}, \mathrm{M}_{2} \mathrm{C}$ formed through dissolution of the cementite and the rise regardless of

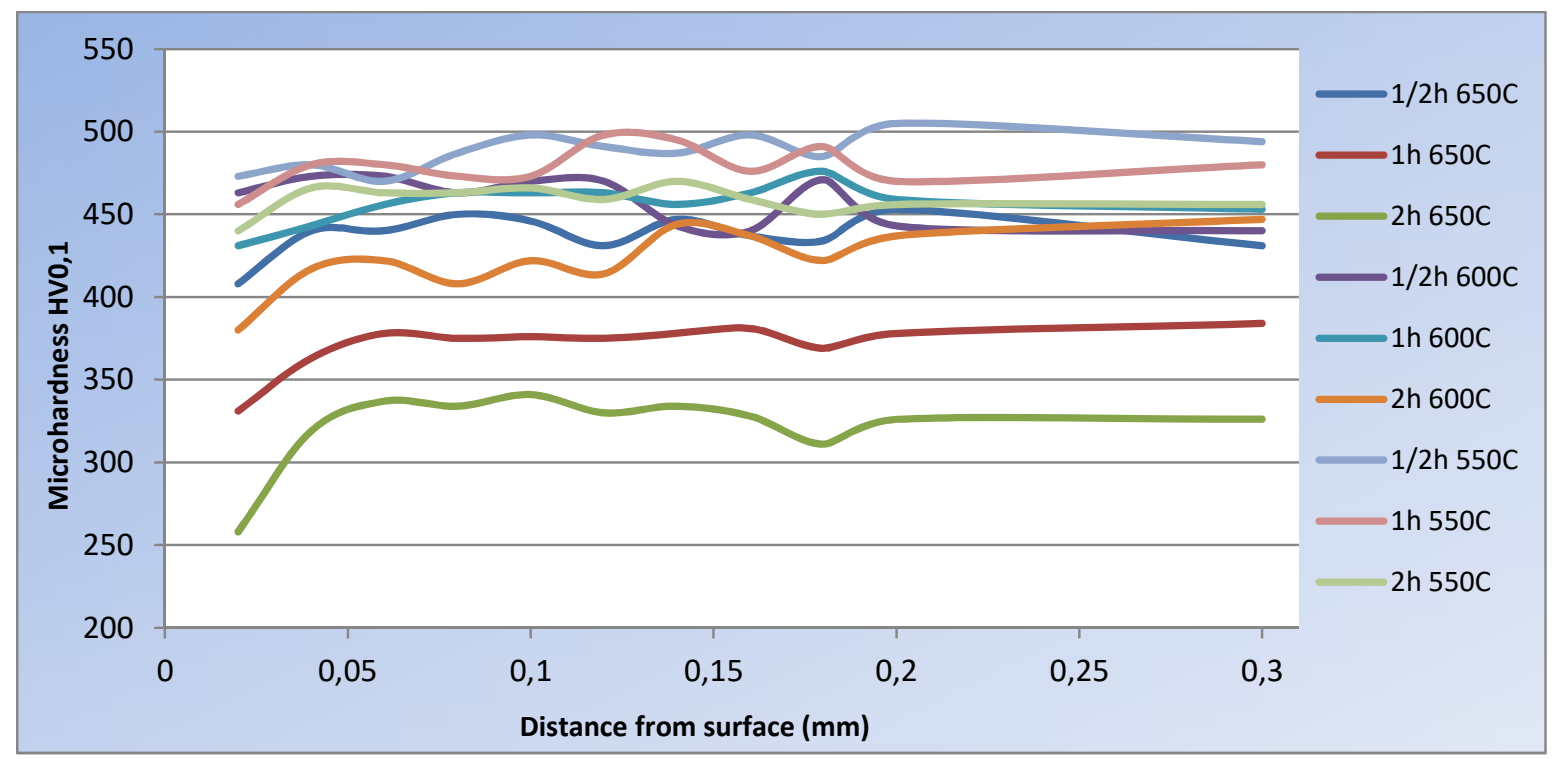

Fig. 13. Effect of annealing temperature and the distribution of hardness of the steel 1.2344 

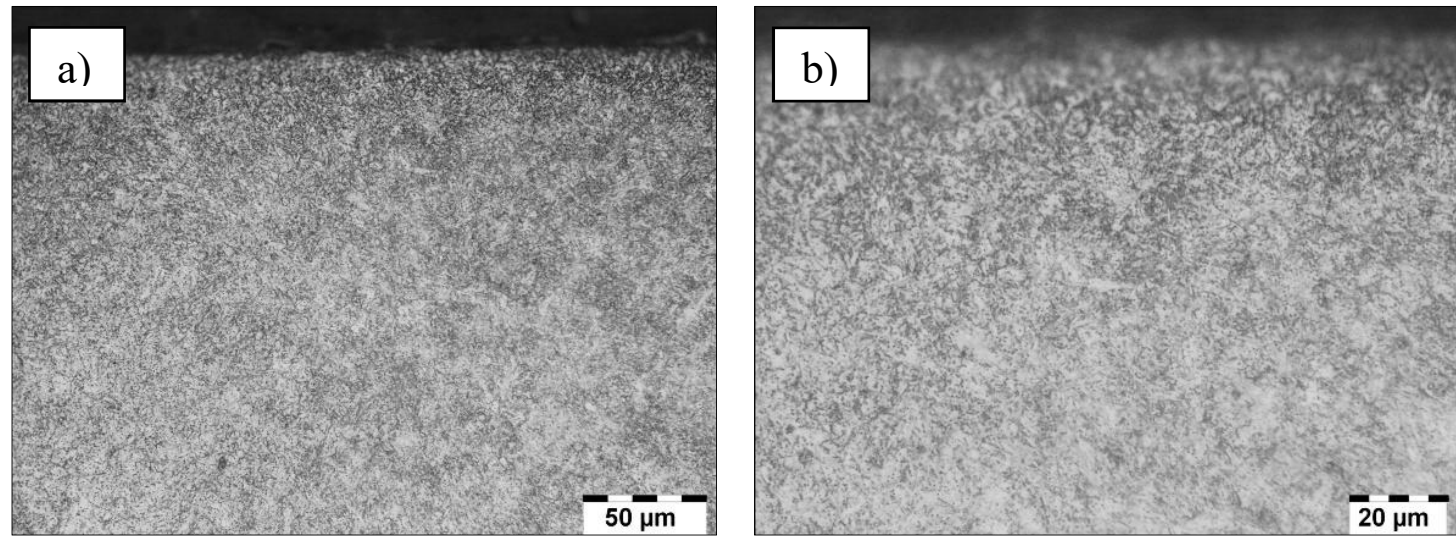

Fig.. 14. The structure of steel 1.2344 after heating at $550^{\circ} \mathrm{C}-2.0 \mathrm{~h}$ a) magnification $500 \times$, b) magnification $1000 \times$, Nital etching
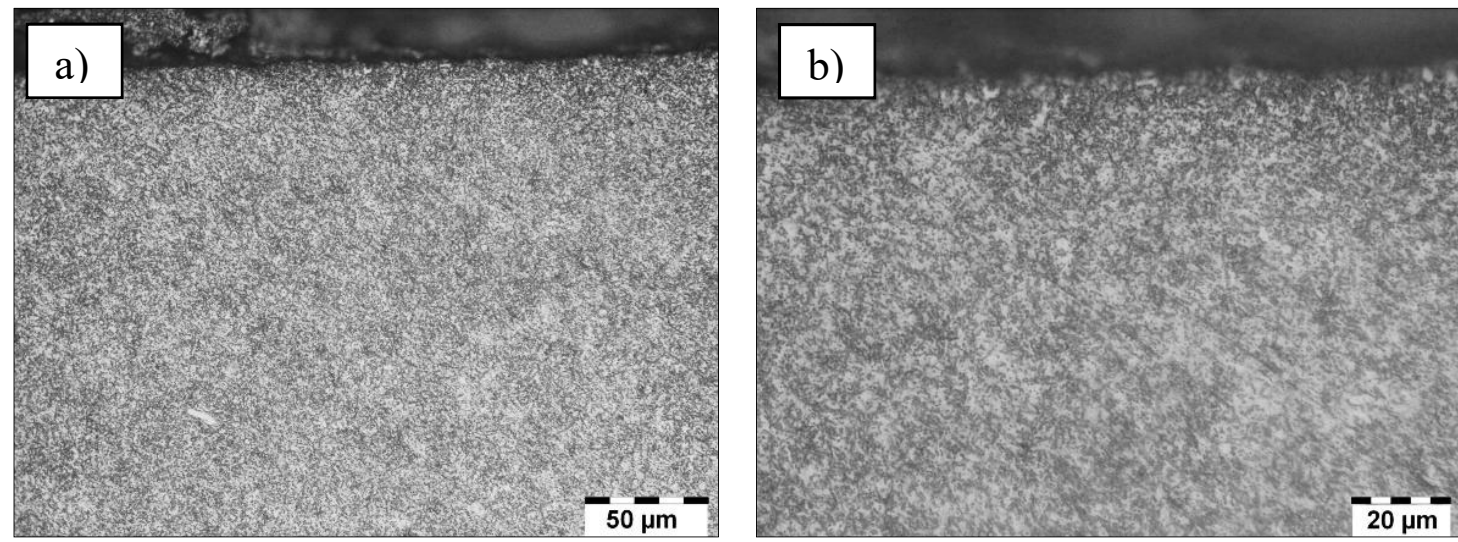

Fig. 15. The structure of steel 1.2344 after heating at $600^{\circ} \mathrm{C}-2.0 \mathrm{~h}$, a) magnification $500 \times$, b) magnification $1000 \times$, Nital etching
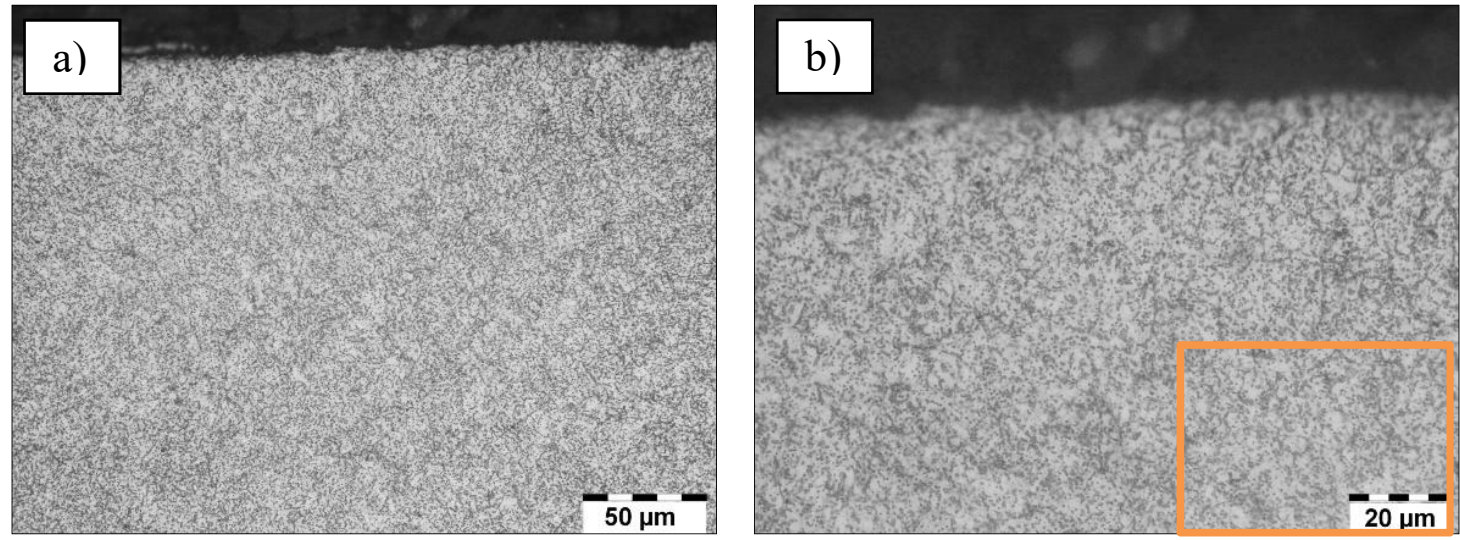

Fig. 16. The structure of steel 1.2344 after heating at $650^{\circ} \mathrm{C}-2.0 \mathrm{~h}$, a) magnification $500 \times$, b) magnification $1000 \times$, Nital etching

existing, new carbide precipitates. Examples of carbide particles are shown in Figure 17.

It can be seen a tendency of coagulation carbides with increasing temperature and time of annealing. Visible is also a lack of clear needles of martensite samples of heated in 600-650LC. Thus the resulting sorbite structure at higher temperatures could be minimal decarburization in the surface layer. This may indicate a decrease in hardness of the surface of the test samples. At higher magnifications you can be observed oxidation of the surface layer of the grain boundaries.
In Figure 18 we can see a clear difference between the surface layer of the tool cooled the second operation, and the surface layer of the first gear operation. Floor tools, with the first operation is not cooled (grease), and we can observe the occurrence of a significant decrease in hardness of about $420 \mathrm{HV}$ and much larger oxide layer on its surface. For a small number of forgings ( $550 \mathrm{pcs}$.) It is also visible difference occurring on the surface of the tools the second operation is a clear net thermal fatigue cracks (Fig. 18b) No cooling results in faster oxidation of tool surfaces for the upsetting tools. Presence of cooling in the second operation results in faster cracking (thermal fatigue). 


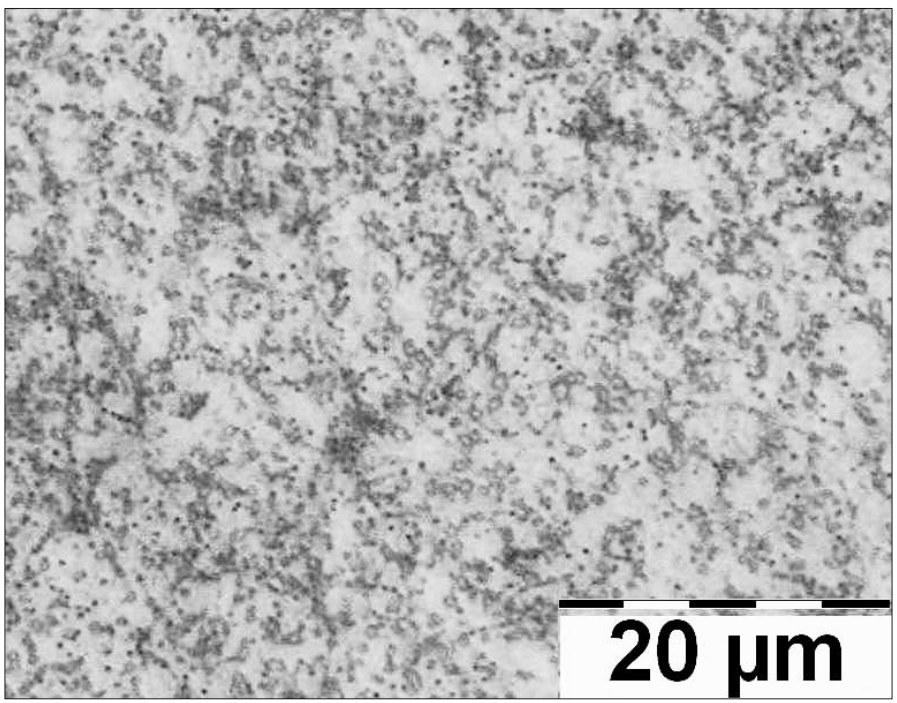

Fig. 17. The structure of steel 1.2344 after heating at $650^{\circ} \mathrm{C}-2.0 \mathrm{~h}$, Enlarge the area from (Fig. 16)
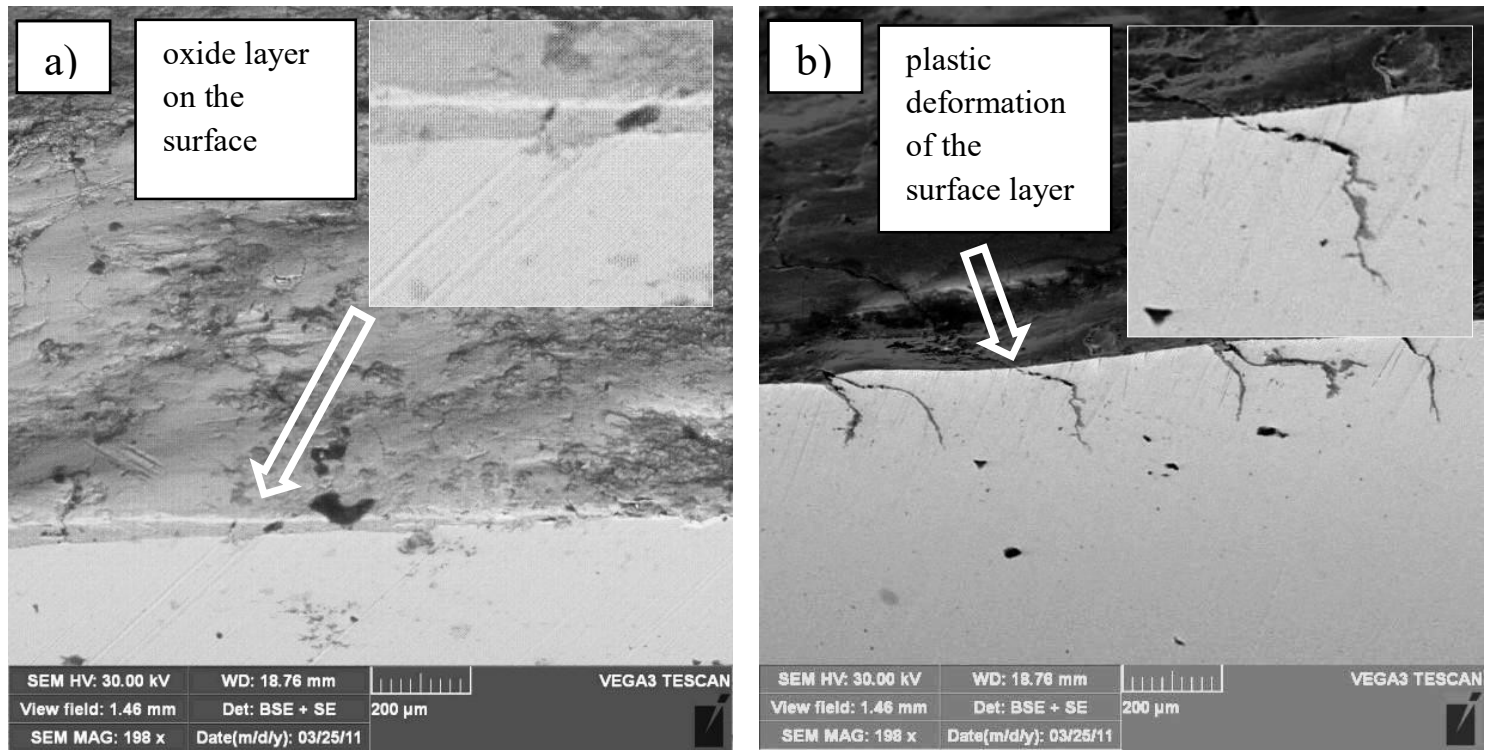

Fig. 18. The surface appearance of tools after a forging 550 pcs of forgings. a) a first operation of the tool, b) the gear of the second operation

\section{Summary and conclusions}

Conditions of work of forging tools are highly complex and each selected case should be considered separately. Literature data indicate that it is possible in some approximate way to describe mathematical relationships phenomena occurring during the operation of forging tools. In the above test results of industrial and laboratory tried to describe the phenomenon of the influence of time and temperature on the durability of tool steels for hot work. Considering the described aspects the following conclusions:

- observed a stronger effect of temperature tools to decrease the hardness of the entire volume of material tools (tools with operations upsetting)

- higher temperatures tools causes oxidation of the surface layer stronger tools, and more intensive decrease in its hardness.
- lower the temperature of the tool and thus larger amplitudes in the outer layer mesh favor the occurrence of thermal fatigue cracks (second operation tool pre-stamping)

- hardness of tools is a function of time $t$ and temperature T of the process.

For accurate to describe the phenomena of wear of forging tools should be aware of other phenomena affecting the tool life: forging temperature, contact time, pressure, type of protective layer and others.

The right approach is such which is considered a real decrease in hardness of the surface layer as a function of time working tools. Such assumptions should always be taken into account when process of modeling the phenomena of wear of tools operating at high temperatures. The research confirmed the assumptions J.H. Kang that the hardness is a function of time. 


\section{REFERENCES}

[1] J.H. Kang, I.W. Park, J.S. Jae, S.S. Kang, A study on die wear model considering thermal softening (II):Application of the suggested wear model. Journal of Materials Processing Technology 96 (1), 53-58 (1999).

[2] J.H. Kang, I.W. Park, J.S. Jae, S.S. Kang, A study on a die wear model considering thermal softening: (I) Construction of the wear model, Journal of Materials Processing Technology 96, 53-58 (1999).

[3] Z. Gronostajski, M. Hawryluk, M. Kaszuba, M. Marciniak, A. Niechajowicz, S. Polak, M. Zwierzchowski, A. Adrian, B. Mrzyglod, J. Durak, „The expert system supporting the assessment of the durability of forging tools". International Journal of Advanced Manufacturing Technology 82 (9), 1973-1991(2016).

[4] M. Zwierzchowski, M. Hawryluk, Structural analysis of hot forging dies with regard to their life. Maintenance and Reliability 2, 31-41 (2009).

[5] M. Zwierzchowski, Analiza metod badania odporności na zmęczenie cieplne Współczesne technologie w budowie maszyn, Lublin, 147-152 (2002).

[6] T. Altan, Cold and hot forging fundamentals and application, ASM Internation, 2005, Ohio.

[7] Z. Gronostajski, M. Kaszuba, M. Hawryluk, M. Zwierzchowski, A review of the degradation mechanisms of the hot forging tools,
Archives of Civil and Mechanical Engineering 14 (4), 528-539 (2014).

[8] D.H. Kima, H.C .Leeb, B.M. Kimc, K.H. Kimd, Estimation of die service life against plastic deformation and wear during hot forging processes, Journal of Materials Processing Technology 212, 1742-1752 (2012).

[9] G.A. Berti, M. Monti, Thermo-mechanical fatigue life assessment of hot forging die steel, Fatigue \& Fracture of Engineering Materials \& Structures 28, 11, 1025-1034 (2005).

[10] J. Ding, Determining fatigue wear using wear particle analysis tools, Practicing Oil Analysis (2003).

[11] M. Hawryluk, Review of selected methods of increasing the life of forging tools in hot die forging processes, Archives of Civil and Mechanical Engineering 16 (4), 845-866 (2016).

[12] B. Behrens, A. Bouguecha, C. Buse, K. Wölki, A. Santangelo, Potentials of in situ monitoring of aluminum alloy forging by acoustic emission Archives of Civil and Mechanical Engineering 16, 4, 724-733 (2016).

[13] L. Rauch, A. Chmura, Z. Gronostajski, M. Zwierzchowski, M. Pietrzyk, Cellular automata model for prediction of crack initiation and propagation in hot forging tools Archives of Civil and Mechanical Engineering 16 (3), 437-447 (2016).

[14] M. Sokolski, P. Sokolski, Strength estimation of the impact zone - A critical area of the tools of the hydraulic hammers, Archives of Civil and Mechanical Engineering 16 (4), 767-776 (2016). 